\title{
Study of double ionic disorder (cationic and anionic) and disorder of two kinds of tin(II) (ionic and covalent) within the same material: the incredibly complex $\mathrm{Ba}_{1-\mathrm{x}} \mathrm{Sn}_{\mathrm{x}} \mathrm{Cl}_{1+\mathrm{y}} \mathrm{F}_{1-\mathrm{y}}$ solid solution and its study by Mössbauer spectroscopy
}

S. Boufas ${ }^{2}$ G. Dénès ${ }^{1}$, J. Kochuparampil ${ }^{1}$, H. Merazig ${ }^{2}$ \& A. Muntasar ${ }^{1}$

${ }^{1}$ Laboratory of Solid State Chemistry and Mössbauer Spectroscopy, Department of Chemistry and Biochemistry, Concordia University, Montréal, Canada

${ }^{2}$ Laboratoire de Chimie Moléculaire, du Contrôle de l'Environnement et des Mesures Physico-Chimiques, Département de Chimie, Université Mentouri, Constantine, Algeria

\begin{abstract}
A doubly disordered $\mathrm{Ba}_{1-\mathrm{x}} \mathrm{Sn}_{\mathrm{x}} \mathrm{Cl}_{1+\mathrm{y}} \mathrm{F}_{1-\mathrm{y}}$ solid solution has been prepared. X-ray diffraction shows that $\mathrm{Ba}$ and $\mathrm{Sn}$ are fully disordered on the $\mathrm{Ba}$ site of the $\mathrm{BaClF}$ structure. In addition, while the two anionic sites remain ordered, for $y>0$ the $y$ $\mathrm{Cl}$ in excess are disordered with the remaining (1-y) $\mathrm{F}$ on the $\mathrm{F}$ site, whereas for $\mathrm{y}<0$, the $(-\mathrm{y})$ excess $\mathrm{F}$ are disordered with the remaining $(1+\mathrm{y}) \mathrm{Cl}$ on the $\mathrm{Cl}$ site. ${ }^{119} \mathrm{Sn}$ Mössbauer spectroscopy showed the $\mathrm{Ba}_{1-\mathrm{x}} \mathrm{Sn}_{\mathrm{x}} \mathrm{Cl}_{1+\mathrm{y}} \mathrm{F}_{1-\mathrm{y}}$ solid solution is a truly unique material. Indeed, in addition to the rarity of being a doubly disordered solid solution over a wide range of chemical composition, it also exhibits a variable mixture of ionic tin(II) $\left(\mathrm{Sn}^{2+}\right.$ stannous ions, with a non-stereoactive lone pair) and covalently bonded tin(II) (with a stereoactive lone pair). A new material, $\mathrm{Ba}_{2} \mathrm{SnCl}_{6}$, has been prepared and its crystal structure solved. It contains octahedrally coordinated $\mathrm{Sn}^{2+}$, with a perfectly non-stereoactive lone pair, for the first time in a chloride. This makes the lone pair a potential charge carrier.
\end{abstract}

Keywords: disordered phases, BaClF structure, Mössbauer spectroscopy, X-ray diffraction, mixed conductivity. 


\section{Introduction}

$\mathrm{BaClF}$ crystallizes in the $\mathrm{PbClF}$ structure. Its structure is a tetragonal distortion of the fluorite-type $\mathrm{BaF}_{2}$, with alternating layers of $\mathrm{F}$ and $\mathrm{Cl}$ ordered parallel to the $c$ axis of the unit-cell (fig. 1), making it an anisotropic structure, in contrast with the isotropic cubic structure of $\mathrm{BaF}_{2}$ (fig. 1) [1]. The $\mathrm{Ba}^{2+}$ ions are bonded to four fluoride ions at the corners of a square, like half of its cubic coordination in $\mathrm{BaF}_{2}$. An apical $\mathrm{Ba}-\mathrm{Cl}$ bond is located in trans-position relative to the fluorine square, with in addition four chloride ions at the corners of a square parallel to the $\mathrm{F}_{4}$ square and rotated by $45^{\circ}$ parallel to $(a, b)$. It results that the barium coordination in $\mathrm{BaClF}$ is $\mathrm{a} \mathrm{BaF}_{4} \mathrm{ClCl}_{4}$ monocapped square antiprism, in contrast with the $\mathrm{BaF}_{8}$ cube found in $\mathrm{BaF}_{2}$. The $\mathrm{BaClF}$ structure is the result of ...F Cl... order of the fluorite structure parallel to the c axis of the unit-cell. An alternate tetragonal distortion of the fluorite structure, also with order parallel to the $c$ axis is the $\mathrm{BaSnF}_{4}$ structure, with the metals being ordered (... Ba Ba Sn Sn...). The structure of $\mathrm{BaSnF}_{4}$ is very strongly two-dimensional (fig. 1).

In the present work, the reaction of barium chloride and tin(II) fluoride in aqueous solutions, at a high $\mathrm{BaCl}_{2} / \mathrm{SnF}_{2}$ ratio, gives a precipitate that appears at first glance, from its X-ray diffraction pattern, to be $\mathrm{BaClF}$. A similar phase, although not completely identical, was obtained by high temperature reaction of a mixture of $\mathrm{BaF}_{2}, \mathrm{BaCl}_{2}$ and $\mathrm{SnF}_{2}$ in dry conditions. The detail investigation of the material obtained, particularly the study of tin by Mössbauer spectroscopy, is presented here. In addition, the first perfectly ionic tin(II) in a chloride fluoride has been discovered in a new compound, $\mathrm{Ba}_{2} \mathrm{SnCl}_{6}$.
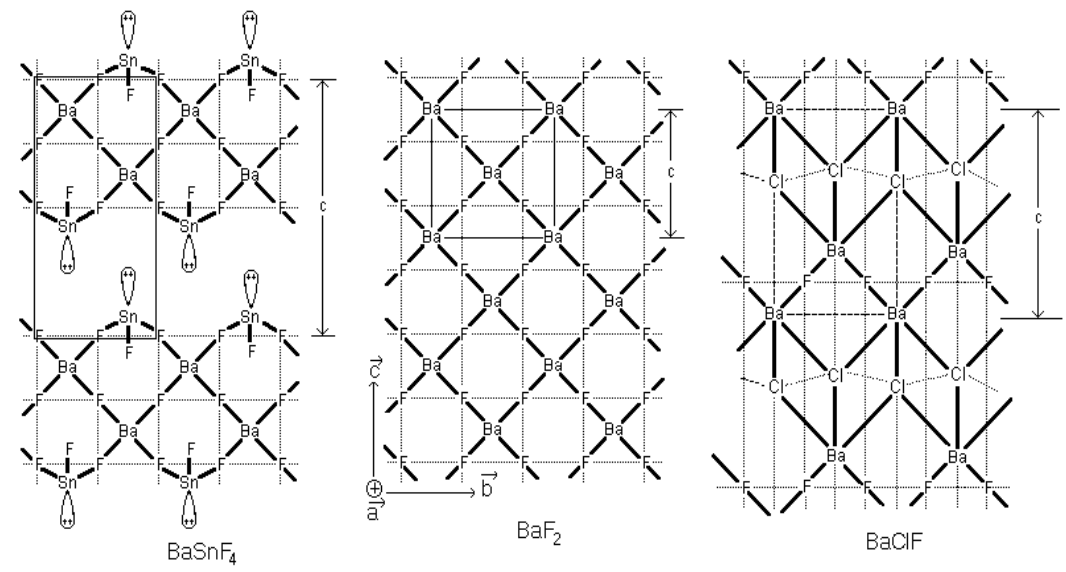

Figure 1: $\quad$ Projection of the crystal structure of $\mathrm{BaSnF}_{4}, \mathrm{BaF}_{2}$ and $\mathrm{BaClF}$.

\section{Experimental}

The "BaClF phase" precipitate was obtained when aqueous solutions of barium chloride and tin(II) fluoride were mixed, at a $\mathrm{X}=\mathrm{BaCl}_{2} /\left(\mathrm{SnF}_{2}+\mathrm{BaCl}_{2}\right)$ molar 
ratio above 0.85 , when barium chloride was added to $\operatorname{tin}(\mathrm{II})$ fluoride $(\mathrm{Ba} \rightarrow \mathrm{Sn}$ ), or the other way around $(\mathrm{Sn} \rightarrow \mathrm{Ba})$. Synthesis under dry conditions was performed when mixtures calculated according to eqn (1) were heated for three days under nitrogen in sealed copper tubes at temperatures varying from 350 to $800{ }^{\circ} \mathrm{C}$.

$$
\frac{1-2 x-y}{2} \mathrm{BaF}_{2}+x \mathrm{SnF}_{2}+\frac{1+y}{2} \mathrm{BaCl}_{2} \rightarrow \mathrm{Ba}_{1-x} \mathrm{Sn}_{x} \mathrm{Cl}_{1+y} F_{1-y}
$$

Crystals of $\mathrm{Ba} 2 \mathrm{SnCl} 6$ were collected from a batch obtained by slow evaporation of an aqueous solution of $\mathrm{BaCl}_{2} \cdot 2 \mathrm{H}_{2} \mathrm{O}$ and $\mathrm{SnCl}_{2} \cdot 2 \mathrm{H}_{2} \mathrm{O}$. Chemical analysis was carried out by use of a Perkin Elmer 503 atomic absorption spectrometer (Ba and Sn), an Orion Research Laboratories 94-09 fluoride ion selective electrode (F), and by argentometry according to the Fajans titration method $(\mathrm{Cl})$. The analytical methods required substantial adjustments in order to eliminate interferences created by the presence of tin and fluorine [2]. X-ray powder diffraction was carried out on a PW-1050/25 Philips diffractometer automated with the SIE RAY $122^{\circledR}$ system from Diffraction Technology, using the $\mathrm{K}_{\alpha}$ radiation of copper $\left(\lambda_{\mathrm{K} \alpha 1}=1.54051 \AA\right)$ and a monochromator. Identification to known phases was done by Search-Match ${ }^{\circledR}$ using the $\mu$ PDSM software from Feinn-Marquat and the JCPDS PDF1 database from the ICDD. Mössbauer spectra were recorded in a TN7200 ${ }^{\circledR}$ multichannel analyzer from Tracor Northern, using an Elscint driving system, a Harshaw (Tl)NaI detector and a $10 \mathrm{mCi} \mathrm{CaSnO}_{3} \gamma$-ray source from Ritverc. All chemical isomer shifts were referenced relative to a standard $\mathrm{CaSnO}_{3}$ absorber. The spectra were fitted using the GMFP5 software.

\section{Results and discussion}

The X-ray powder diffraction pattern of the precipitate (fig. 2b) has the same set of peaks as $\mathrm{BaClF}$ (fig. 2c), at the same positions, and therefore, it seems that the product obtained is simply BaClF. This seemed confirmed by Search-Match ${ }^{\circledR}$ that resulted in $\mathrm{BaClF}$ being the only reasonable match. Although the match was reasonably good (Similarity Index SI $>150$ and all 15 peaks matched), a close examination of the peak position revealed a small, but significant shift, shown by arrows on figure $3 \mathrm{a}$, relative to unsubstituted $\mathrm{BaClF}$ (fig. 3b). The shift of all peaks is consistent with a $0.91 \%$ decrease of the $a$ parameter and a $0.97 \%$ increase of $c$, while the unit-cell volume decreases by $0.86 \%$ and the $c / a$ tetragonal distortion increases by $1.89 \%$. The change of unit-cell parameters suggests a change of chemical composition. A logical change was the substitution of a fraction of $\mathrm{Ba}$ by $\mathrm{Sn}$, to give non-stoichiometric $\mathrm{Ba}_{1-\mathrm{x}} \mathrm{Sn}_{\mathrm{x}} \mathrm{ClF}$. Chemical analysis was performed to determine the tin molar fraction $x$, and it showed that the compound is also non-stoichiometric for the anions, such that the formula is best written as $\mathrm{Ba}_{1-\mathrm{x}} \mathrm{Sn}_{\mathrm{x}} \mathrm{Cl}_{1+\mathrm{y}} \mathrm{F}_{1-\mathrm{y}}(\mathrm{x}=0.15, \mathrm{y}=0.11)$, to show it is a substituted $\mathrm{BaClF}$ phase, as shown by $\mathrm{X}$-ray diffraction. 


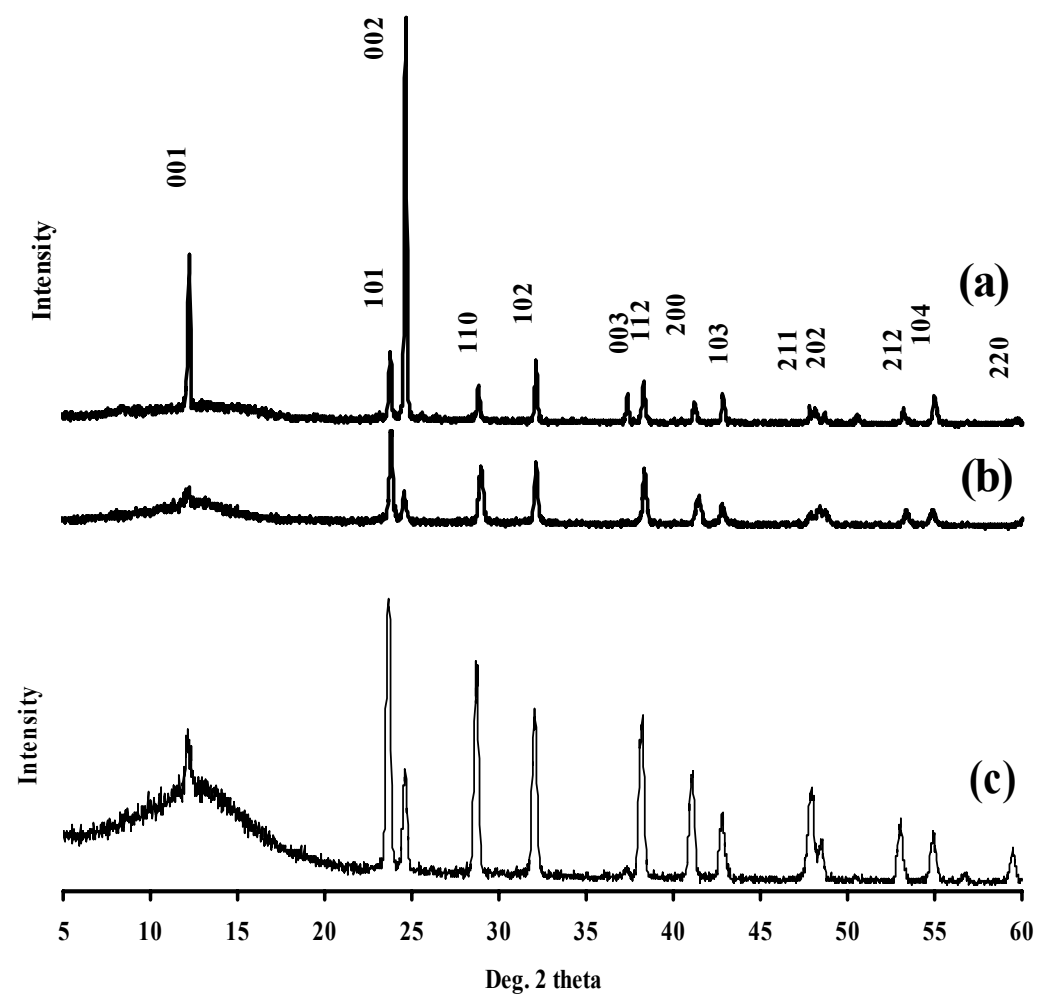

Figure 2: X-ray diffraction of (a) $\mathrm{Ba}_{1-\mathrm{x}} \mathrm{Sn}_{\mathrm{x}} \mathrm{Cl}_{1+\mathrm{y}} \mathrm{F}_{1-\mathrm{y}}$ prepared by the dry method $\left(\mathrm{x}=0.150, \mathrm{y}=0.050,43\right.$ hours at $\left.500{ }^{\circ} \mathrm{C}\right)$, (b) precipitated $\mathrm{Ba}_{1-\mathrm{x}} \mathrm{Sn}_{\mathrm{x}} \mathrm{Cl}_{1+\mathrm{y}} \mathrm{F}_{1-\mathrm{y}}(\mathrm{X}=0.923)$, (c) $\mathrm{BaClF}$ precipitated by addition of $\mathrm{HF}_{(a q)}$ to a solution of $\mathrm{BaCl}_{2} \cdot 2 \mathrm{H}_{2} \mathrm{O}$.

Preparations carried out by the dry method yielded a material that also gives the $\mathrm{BaClF}$ diffraction pattern (fig. 2a). A wide double non-stoichiometric solid solution was obtained: $0 \leq x \leq 0.25,-0.15 \leq y \leq 0.25$. The inversion of the relative intensities of the (002) and (110) peaks could be in part due to the change of chemical composition. It is likely that it is mostly due to preferred orientation favoring the (001) peaks in the latter, i.e. the material tends to cleave parallel to $(a, b)$. This is consistent with the crystal structure (fig. 1): the long $\mathrm{Ba}-\mathrm{Cl}$ bonds ( $\mathrm{Cl}$ atoms at the corners of a square) are the weak links. In addition, figure 3 shows that the peak shift in the solid solution prepared by the dry method is negligible, and it was found it changes very little with the composition parameters $x$ and $y$. The different unit-cell parameters of the solid solution prepared by the two methods shows that something differentiates them from one another, although both are doubly disordered $\mathrm{BaClF}$ structures. For these 
disordered phases, only average $\mathrm{Ba} / \mathrm{Sn}$ values can be obtained by diffraction alone. Could the difference be due to the way tin binds to the BaClF network?
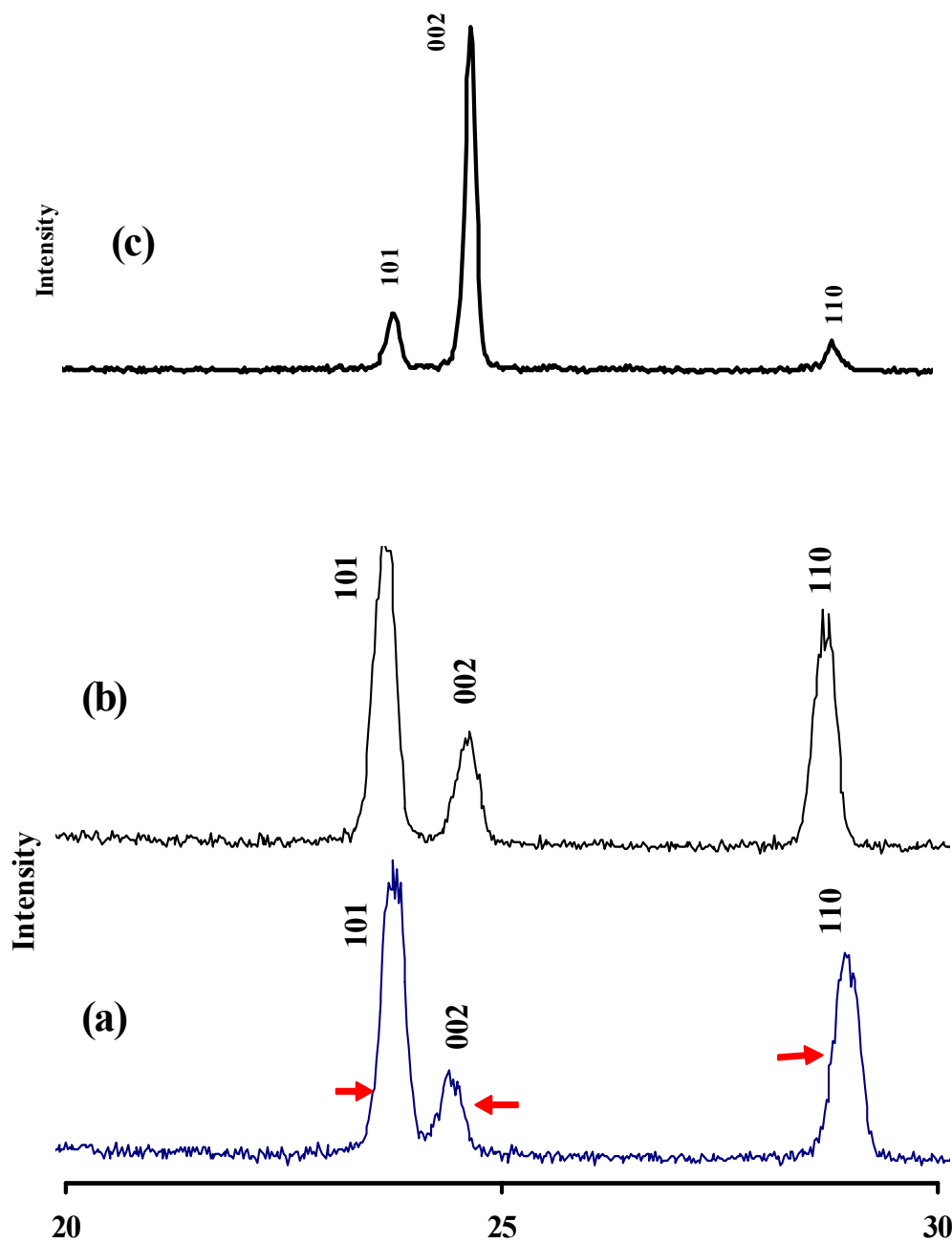

Deg. 2 theta

Figure 3: Enlargement of a portion of the $\mathrm{X}$-ray powder diffraction pattern of: (a) $\mathrm{Ba}_{1-\mathrm{x}} \mathrm{Sn}_{\mathrm{x}} \mathrm{Cl}_{1+\mathrm{y}} \mathrm{F}_{1-\mathrm{y}}$ prepared by the dry method $(\mathrm{x}=0.150, \mathrm{y}=$ $0.050,43$ hours at $500{ }^{\circ} \mathrm{C}$ ), (b) $\mathrm{BaClF}$ precipitated by addition of $\mathrm{HF}_{(a q)}$ to a solution of $\mathrm{BaCl}_{2} \cdot 2 \mathrm{H}_{2} \mathrm{O}$, (c) precipitated $\mathrm{Ba}_{1-\mathrm{x}} \mathrm{Sn}_{\mathrm{x}} \mathrm{Cl}_{1+\mathrm{y}} \mathrm{F}_{1-}$ y $(X=0.923)$. 

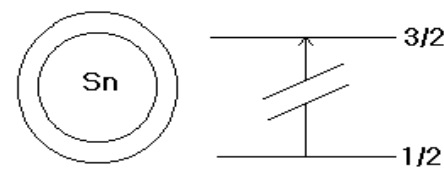

(a)
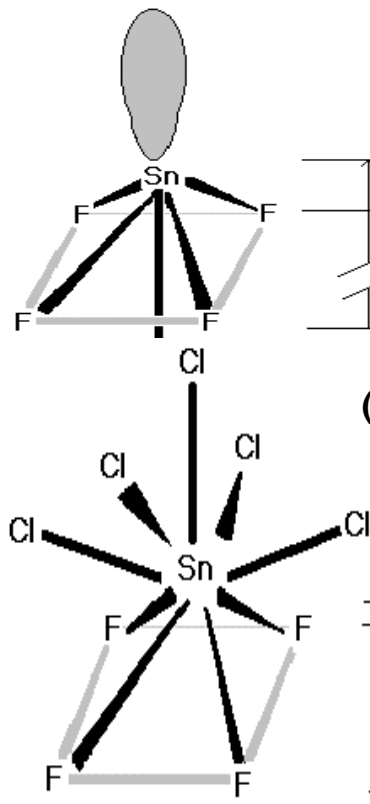

(b)
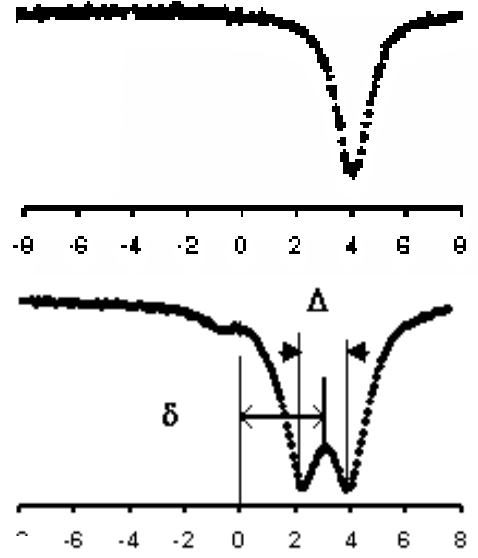

Velocity ( m m is)

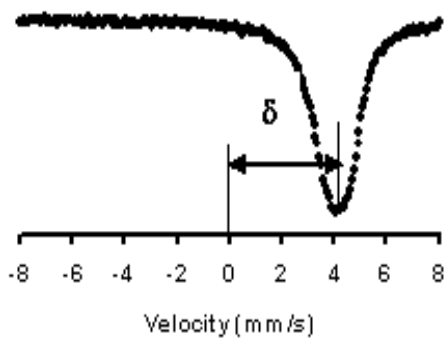

$\mid \pm 1 / 2>$ $\pm 3 / 2>$

(c)

Figure 4: Electrical monopolar and electrical quadrupolar interactions generated by different kinds of divalent tin, and their effect on the Mössbauer spectrum: (a) unhybridized lone pair (e.g. semiconducting $\mathrm{CsSnBr}_{3}$ ), (b) hybridized lone pair (e.g. $\mathrm{BaSnF}_{4}$ ), (c) unhybridized lone pair in the case of $\mathrm{Ba}_{1-\mathrm{x}} \mathrm{Sn}_{\mathrm{x}} \mathrm{Cl}_{1+\mathrm{y}} \mathrm{F}_{1-\mathrm{y}}$ discovered in the present work.

A selective probing of the tin sites, that ignores barium, is required. Mössbauer spectroscopy of the ${ }^{119} \mathrm{Sn}$ nuclide probes the tin sites only, regardless of crystallinity or order/disorder. Figure 4 shows the expected Mössbauer spectrum for the modes of bonding of divalent tin. Tin belongs to group 14 and period 5 of the periodic table of the elements, and therefore it has 4 valence electrons. It results that it forms two stable oxidation states, +2 and +4 . In the suboxidation state +2 , tin has a non-bonded electron pair (lone pair). Two types of bonding can be found in halides: ionic bonding (most iodides and some bromides) or covalent bonding (all fluorides and chlorides, and most bromides). When bonding is ionic, the tin lone pair is located on the $5 s$ native orbital (nonstereoactive lone pair). Figure $4 \mathrm{a}$ shows that in the case of ionic bonding in an undistorted coordination, the $5 s$ orbital is perfectly spherical and there is no 
electric field gradient (efg) at the $\mathrm{Sn}^{2+}$ site. It results no splitting of the nuclear levels, and therefore only one nuclear transition takes place $(1 / 2 \rightarrow 3 / 2)$, and a single Mössbauer absorption line is observed. This contrasts with the case of covalent bonding, where the tin lone pair is located on one of the hybrid orbitals (stereoactive lone pair). This lone pair is highly axial and therefore generates a large efg, $\left(\mathrm{V}_{\mathrm{zz}}\right)_{\mathrm{val}}$. In addition, the stereoactive lone pair distorts very strongly the tin polyhedron of coordination, which generates another term of the efg, $\left(\mathrm{V}_{\mathrm{zz}}\right)_{\text {latt}}$. The overall effect is the splitting of the first excited state which results in two nuclear transitions, and the Mössbauer spectrum is a doublet, with a large quadrupole splitting $\Delta$ (fig. $4 \mathrm{~b}$ ). In addition, the higher the valence $s$ electron density acting at tin, the higher the isomer shift $\delta$, i.e. the line shift relative to a $\mathrm{CaSnO}_{3}$ standard. As can be seen from figure 4, this makes the isomer shift of $\mathrm{Sn}^{2+}, 4.0-4.1 \mathrm{~mm} / \mathrm{s}$ ( $5 \mathrm{~s}$ electron density concentrated around the tin atom) higher than that for $\mathrm{Sn}(\mathrm{II})_{\mathrm{cov}}, 2.5-3.5 \mathrm{~mm} / \mathrm{s}$ ( $5 \mathrm{~s}$ electron density pulled away in hybrid orbitals).

The ambient temperature spectrum of precipitated $\mathrm{Ba}_{1-\mathrm{x}} \mathrm{Sn}_{\mathrm{x}} \mathrm{Cl}_{1+\mathrm{y}} \mathrm{F}_{1-\mathrm{y}}$ is a single line at $4.07 \mathrm{~mm} / \mathrm{s}$ (fig. $5 \mathrm{a}_{1}$ ) which shows that tin is present in the form of $\mathrm{Sn}^{2+}$ stannous ions. For the $\mathrm{Ba}_{1-\mathrm{x}} \mathrm{Sn}_{\mathrm{x}} \mathrm{Cl}_{1+\mathrm{y}} \mathrm{F}_{1-\mathrm{y}}$ solid solution prepared in dry conditions, the Mössbauer spectrum is a function of the $x$ and $y$ composition parameters. For a high tin content $(x=0.225)$, the spectrum is also a single line at ca. $4 \mathrm{~mm} / \mathrm{s}$ if Cl/F>1 $(y=0.25)$, and therefore bonding is ionic (fig. $\left.5 \mathrm{~b}_{1}\right)$. For the same $x$ value and $\mathrm{Cl} / \mathrm{F}<1(\mathrm{y}=-0.15)$, the tin(II) region of the spectrum is a very highly asymmetric doublet, which is actually due to the sum of a doublet and a single line. Since for fluorides, the high velocity line of a doublet is at about $4 \mathrm{~mm} / \mathrm{s}$, it adds to the single line of ionic tin to makes a spectrum that looks like a strongly asymmetric doublet. Therefore, at high tin content, and when there is more fluorine than chlorine, the $\mathrm{Ba}_{1-\mathrm{x}} \mathrm{Sn}_{\mathrm{x}} \mathrm{Cl}_{1+\mathrm{y}} \mathrm{F}_{1-\mathrm{y}}$ solid solution contains a mixture of $\mathrm{Sn}^{2}+$ ions and covalently bonded tin(II). The line at ca. 0 $\mathrm{mm} / \mathrm{s}$ in the spectra of figures $5 \mathrm{c}_{1}$ and $5 \mathrm{c}_{2}$ is due to a tin(IV) impurity generated by surface oxidation of the particles. This is common in tin(II) compounds. The ambient temperature spectra have a highly unequal intensity, and strangely enough, the poorest in tin is the strongest (fig. $5 \mathrm{a}_{1}$ ). In addition, the spectrum of figure $5 b_{1}$ is much weaker than that of figure $5 c_{1}$, even though they contain exactly the same amount of tin. The line intensity is a function of the recoilless fraction $f_{a}$, which is itself a function of bond strength.

All the Mössbauer observations make it possible to build a model of tin bonding in $\mathrm{Ba}_{1-\mathrm{x}} \mathrm{Sn}_{\mathrm{x}} \mathrm{Cl}_{1+\mathrm{y}} \mathrm{F}_{1-\mathrm{y}}$ solid solution: (i) at low tin concentration (small $x$ ), like in the precipitated solid solution, due to dilution tin is isolated from other tin atoms, the solid network is determined by the size of the $\mathrm{Ba}^{2+}, \mathrm{Cl}^{-}$and $\mathrm{F}^{-}$ions, and since tin occupies a barium site, it takes the same mode of bonding, i.e. ionic (figs. 6a); (ii) at high tin content $(\mathrm{x}=0.25)$, the tin concentration is high enough to have some tin clustering, and in an excess of fluorine $(y=-0.15)$ each tin atom is connected by bridging fluorine, and this result in covalently bonded tin with a stereoactive lone pair (fig. $6 \mathrm{~b}$ ). The sample of figure $5 \mathrm{c}_{1}$ contains a mixture of the two models of figures $6 \mathrm{a}$ and $6 \mathrm{~b}$. However, at the same tin concentration ( $\mathrm{x}$ $=0.25)$, in the presence of an excess of chlorine $(\mathrm{y}=0.25)$, the excess $\mathrm{Cl}$ is likely 
to coordinate tin where there is more room than around barium, due to the smallest size of tin, and this probably creates a situation similar to anhydrous $\mathrm{SnCl}_{2}$. Mössbauer spectroscopy has shown that ionic bond is present in $\mathrm{SnCl}_{2}$. This is probably the reason for the single $\mathrm{Sn}^{2+}$ line of figure $5 b_{1}$. The weaker Sn$\mathrm{Cl}$ bonds, compared to $\mathrm{Sn}-\mathrm{F}$ bonds, are the reason for the very weak lattice (extremely weak line intensity at ambient temperature).
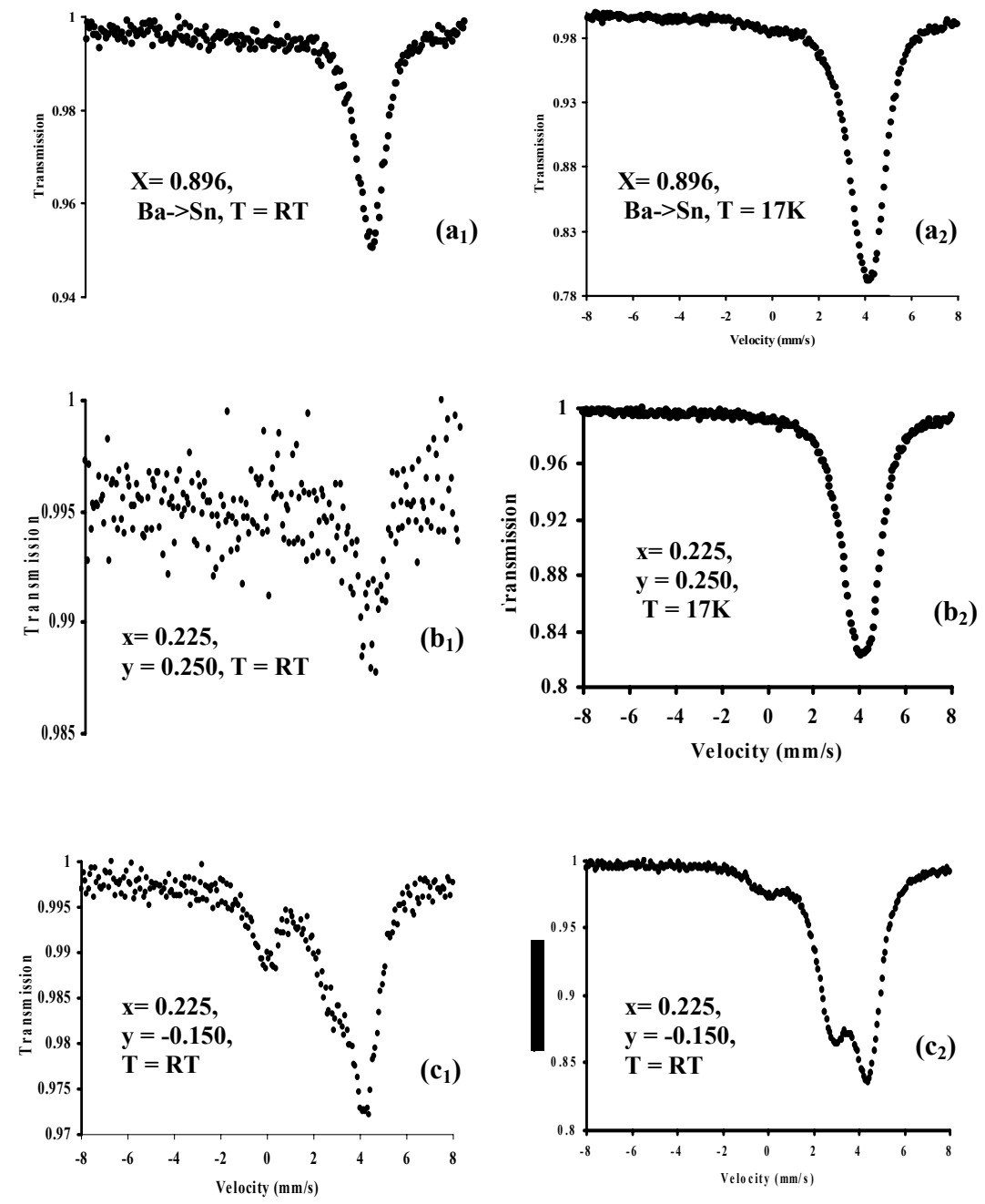

Figure 5: $\quad{ }^{119} \mathrm{Sn}$ Mössbauer spectrum at $293 \mathrm{~K}\left(\mathrm{a}_{1}, \mathrm{~b}_{1}, \mathrm{c}_{1}\right)$ and $17 \mathrm{~K}\left(\mathrm{a}_{2}, \mathrm{~b}_{2}, \mathrm{c}_{2}\right)$ of samples: $\left(\mathrm{a}_{1} \& \mathrm{a}_{2}\right)$ AM-1273 (precipitated at ambient conditions, $\mathrm{X}=0.896, \mathrm{Ba} \rightarrow \mathrm{Sn}),\left(\mathrm{b}_{1} \& \mathrm{~b}_{2}\right)$ AM-1270 (dry method, $\mathrm{x}=0.225, \mathrm{y}$ $=0.250),\left(c_{1} \& c_{2}\right)$ AM-1148 (dry method, $\left.x=0.225, y=-0.150\right)$. 
(a)

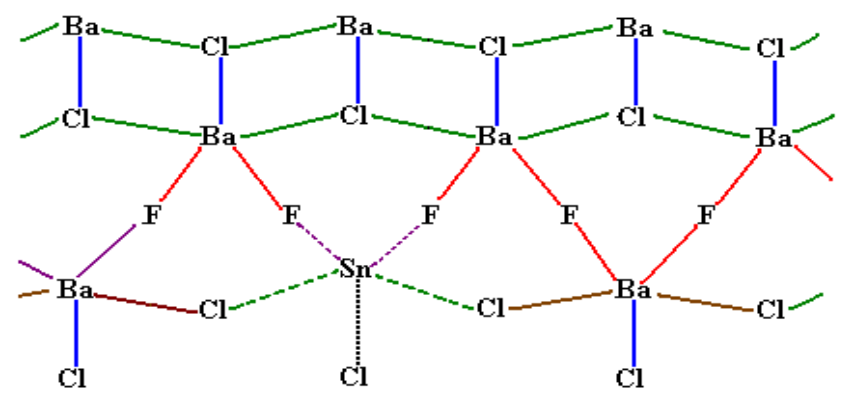

(b)

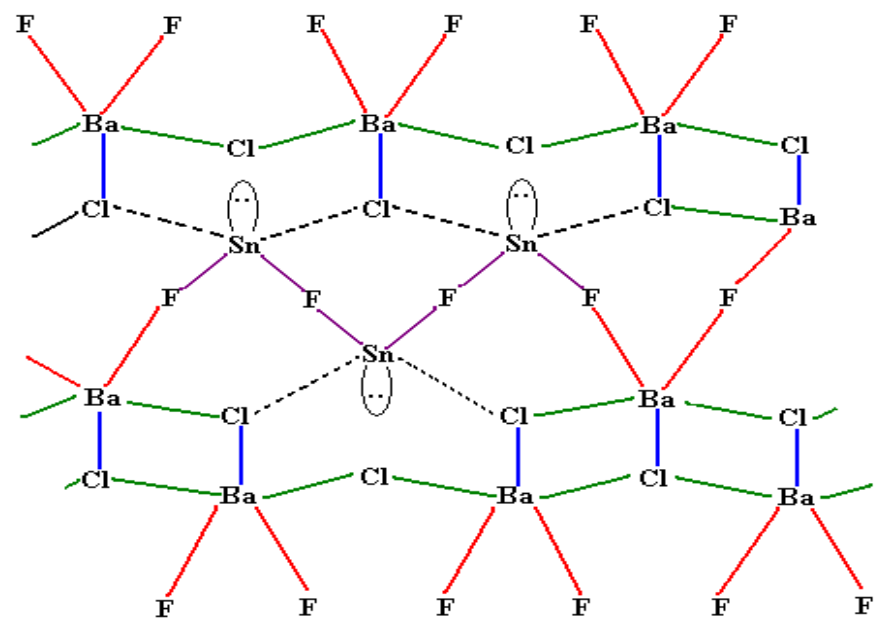

Figure 6: Bonding model in $\mathrm{Ba}_{1-\mathrm{x}} \mathrm{Sn}_{\mathrm{x}} \mathrm{Cl}_{1+\mathrm{y}} \mathrm{F}_{1-\mathrm{y}}$ : (a) ionic bonding for isolated $\mathrm{Sn}^{2+}$ ions at low $x$, (b) covalent bonding to $\mathrm{Sn}(\mathrm{II})$ in Sn clusters at higher $x$.

On cooling to $17 \mathrm{~K}$, thermal motion is frozen and therefore the Mössbauer spectra are stronger. Since weak and strong lattices have their thermal motion frozen, the difference between them is very small at low temperature, and weak lattices benefit more from cooling (fig. $5 b_{1}$ ). The reason for some of the difference between the precipitated solid solution and that prepared in dry conditions is unclear at this point. However, our current research under progress has shown that there is a phase transition on heating the precipitates, to give a high temperature phase metastable at ambient temperature, that is similar to the samples prepared in dry conditions at ambient conditions.

The theoretical spectrum for purely ionic tin(II), i.e. the stannous $\mathrm{Sn}^{2+}$ ion, is a single line at high velocity (ca. $4.1 \mathrm{~mm} / \mathrm{s}$ ), shown on figure $4 \mathrm{a}$. However, $\mathrm{SnCl}_{2}$ has an orthorhombic structure, and therefore the tin site is distorted, which results in a small efg due to possible polarization of the lone pair and site distortion, therefore one can expect a moderate broadening of the line. The same 
applies to ionic tin in $\mathrm{Ba}_{1-\mathrm{x}} \mathrm{Sn}_{\mathrm{x}} \mathrm{Cl}_{1+\mathrm{y}} \mathrm{F}_{1-\mathrm{y}}$, where the presence of a mixture of fluorine and chlorine around tin also contributes to the efg (fig. 4c). Therefore, no strictly purely ionic tin(II) had been obtained before in a chloride or in a fluoride. Now, this has been done: crystals of $\mathrm{Ba}_{2} \mathrm{SnCl}_{6}$ were obtained and its crystal structure has been solved. The unit-cell is cubic, and tin is located in an undistorted octahedral site (fig. 7). This is the first case of a perfectly spherical, i.e. completely non-stereoactive, lone pair, in a tin(II) chloride. Efforts are now focusing on producing a sufficient quantity in order to collect its Mössbauer spectrum. It should have the narrowest possible line for $\mathrm{Sn}^{2+}$, and give, for the first time, the true isomer shift of purely ionic tin in a chloride matrix. The full crystal structure of $\mathrm{Ba}_{2} \mathrm{SnCl}_{6}$ will be published elsewhere.

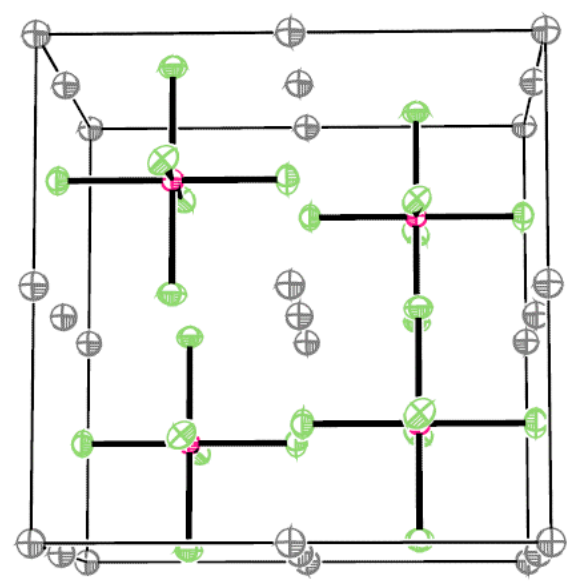

Figure 7: $\quad$ Crystal structure of $\mathrm{Ba}_{2} \mathrm{SnCl}_{6}$.

\section{Conclusion}

The combination of Mössbauer spectroscopy with X-ray powder diffraction has made possible a deep understanding of tin bonding in the $\mathrm{Ba}_{1-\mathrm{x}} \mathrm{Sn}_{\mathrm{x}} \mathrm{Cl}_{1+\mathrm{y}} \mathrm{F}_{1-\mathrm{y}}$ solid solution. For the first time, a doubly disordered solid solution, with $\mathrm{Ba}^{2+}$ ions, $\mathrm{Sn}^{2+}$ ions and covalently bonded tin(II) disordered on the same site has been obtained. In addition, this is the first time that ionic tin(II) and covalently bonded tin(II) have been reported to be present in the same sample, and also to be varied by changing the stoichiometry.

\section{Acknowledgements}

This work was made possible by the support of Concordia University, the Natural Science and Engineering Research Council of Canada and the université Mentouri. Grateful thanks are also due to the Procter and Gamble Co. (Mason, Ohio) for supporting our Mössbauer laboratory. 
High Performance Structures and Materials III 321

\section{References}

[1] Flahaut, J., Les structures de type PbFCl $\left(\mathrm{EO}_{\mathrm{I}}\right)$ et type anti-Fe ${ }_{2} \mathrm{As}(\mathrm{C} 38)$ des composés ternaires à deux anions MXY. J. Solid State Chem., 9, pp. 124-131, 1974.

[2] Muntasar, A., Preparation, characterization and properties of novel materials in the $\mathrm{BaCl}_{2} / \mathrm{SnF}_{2}$ system, $\mathrm{PhD}$ thesis, Concodia University, Montreal, pp. 39-89, 2002. 